1998-09-21

\title{
An analysis of temperature dependent photoluminescence line shapes in InGaN
}

John S. Colton

john_colton@byu.edu

K. L. Teo

P. Y. Yu

E. R. Weber

M. F. Li

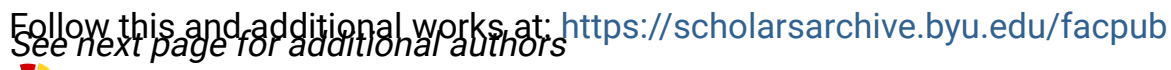

Part of the Astrophysics and Astronomy Commons, and the Physics Commons

\section{Original Publication Citation}

An analysis of temperature dependent photoluminescence lineshapes in InGaN, K.L. Teo, J.S. Colton, P.Y. Yu, E.R. Weber, M.F. Li, W. Liu, K. Uchida, H.Tokunaga, N. Akutsu and K. Matsumoto, Appl. Phys. Lett.73, 1697 (1998). The original version may be found at: http://apl.aip.org/ resource/1/applab/v73/i12/p1697_s1

\section{BYU ScholarsArchive Citation}

Colton, John S.; Teo, K. L.; Yu, P. Y.; Weber, E. R.; Li, M. F.; Lui, W.; Uchida, K.; Tokunaga, H.; Akutsu, N.; and Matsumoto, K., "An analysis of temperature dependent photoluminescence line shapes in InGaN" (1998). Faculty Publications. 642.

https://scholarsarchive.byu.edu/facpub/642

This Peer-Reviewed Article is brought to you for free and open access by BYU ScholarsArchive. It has been accepted for inclusion in Faculty Publications by an authorized administrator of BYU ScholarsArchive. For more information, please contact ellen_amatangelo@byu.edu. 


\section{Authors}

John S. Colton, K. L. Teo, P. Y. Yu, E. R. Weber, M. F. Li, W. Lui, K. Uchida, H. Tokunaga, N. Akutsu, and K. Matsumoto 


\section{AIP Appiled Physics \\ Letters}

\section{An analysis of temperature dependent photoluminescence line shapes in InGaN}

K. L. Teo, J. S. Colton, P. Y. Yu, E. R. Weber, M. F. Li et al.

Citation: Appl. Phys. Lett. 73, 1697 (1998); doi: 10.1063/1.122249

View online: http://dx.doi.org/10.1063/1.122249

View Table of Contents: http://apl.aip.org/resource/1/APPLAB/v73/i12

Published by the American Institute of Physics.

\section{Related Articles}

Effects of pumping on propagation velocities of confined exciton polaritons in GaAs/AlxGa1-xAs double heterostructure thin films under resonant and non-resonant probe conditions

J. Appl. Phys. 113, 013514 (2013)

Sub-250nm light emission and optical gain in AIGaN materials

J. Appl. Phys. 113, 013106 (2013)

Infrared to vacuum-ultraviolet ellipsometry and optical Hall-effect study of free-charge carrier parameters in Mgdoped InN

J. Appl. Phys. 113, 013502 (2013)

Nanomechanical and optical properties of highly a-axis oriented AIN films

Appl. Phys. Lett. 101, 254102 (2012)

$2.8 \mu \mathrm{m}$ emission from type-I quantum wells grown on $\ln A s x \mathrm{P} 1-\mathrm{x} / \mathrm{InP}$ metamorphic graded buffers Appl. Phys. Lett. 101, 251107 (2012)

\section{Additional information on Appl. Phys. Lett.}

Journal Homepage: http://apl.aip.org/

Journal Information: http://apl.aip.org/about/about_the_journal

Top downloads: http://apl.aip.org/features/most_downloaded

Information for Authors: http://apl.aip.org/authors

\section{ADVERTISEMENT}

\section{AIP Applied Physics Letters}

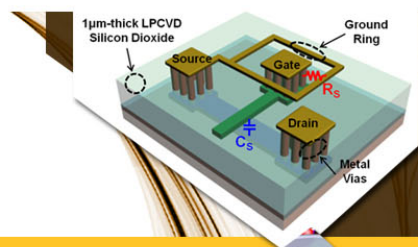

SURFACES AND INTERFACES

Focusing on physical, chemical, biological structural, optical, magnetic and electrical properties of surfaces and interfaces, and more..

\section{EXPLORE WHAT'S NEW IN APL}

SUBMIT YOUR PAPER NOW!
ENERCY CONVERSION AND STORACE 


\title{
An analysis of temperature dependent photoluminescence line shapes in InGaN
}

\author{
K. L. Teo, J. S. Colton, and P. Y. Yu ${ }^{\text {a) }}$ \\ Department of Physics, University of California, and Materials Science Division, Lawrence Berkeley \\ National Laboratory, Berkeley, California 94720 \\ E. R. Weber \\ Department of Materials Science and Mineral Engineering, University of California, and Materials Science \\ Division, Lawrence Berkeley National Laboratory, Berkeley, California 94720 \\ M. F. Li and W. Liu \\ Department of Electrical Engineering, Center for Optoelectronics, National University of Singapore, \\ Singapore 11920 \\ K. Uchida \\ Department of Communications and Systems, The University of Electro-Communications, \\ 1-5-1 Choufugaoka, Choufu, Tokyo 182, Japan \\ H. Tokunaga, N. Akutsu, and K. Matsumoto \\ Nippon Sanso Co., Tsukuba Laboratories, 10 Ohkubo Tsukuba, Ibaraki, 300-26, Japan
}

(Received 7 April 1998; accepted for publication 21 July 1998)

\begin{abstract}
Photoluminescence (PL) line shapes in InGaN multiple quantum well structures have been studied experimentally and theoretically between 10 and $300 \mathrm{~K}$. The higher temperature PL spectra can be fitted quantitatively with a thermalized carrier distribution and a broadened joint-density-of-states. The low temperature PL line shapes suggest that carriers are not thermalized, as a result of localization by band-gap fluctuations. We deduce a localization energy of $\sim 7 \mathrm{meV}$ as compared with an activation energy of $\sim 63 \mathrm{meV}$ from thermal quenching of the PL intensity. We thus conclude that this activation energy and the band-gap fluctuation most likely have different origins.

(C) 1998 American Institute of Physics. [S0003-6951(98)03038-1]
\end{abstract}

Semiconductor alloys such as $\operatorname{In}_{x} \mathrm{Ga}_{1-x} \mathrm{~N}$ (referred to as $\mathrm{InGaN}$ ) have become important in fabricating blue-green light emitting diodes (LEDs) and laser diodes (LDs). ${ }^{1}$ Despite their commercial success, the optical emission properties are not completely understood. The nature of the electron-hole pair producing the emission in $\mathrm{InGaN}_{\text {has }}$ been controversial. For example, Narukawa et al. ${ }^{2}$ have suggested that recombination in InGaN multiple quantum well systems could occur in In-rich regions acting as quantum dots. Other authors have attributed the emission to the recombination of excitons localized either by In compositional fluctuations ${ }^{3}$ or at the band tail states. ${ }^{4}$

In this letter we study the PL line shapes in a InGaN sample and analyze the temperature dependence of its line shape, using a single broadening parameter. We compare our results in InGaN with a related and better understood family of ternary alloys, InGaP. The line shape similarity allows us to understand the behavior of photoexcited carriers in InGaN.

Our InGaN multiple quantum well (MQW) samples were grown by metalorganic chemical vapor deposition (MOCVD) on $c$-plane sapphire and consist of the following sequence: sapphire substrate/GaN $(2.2 \mu \mathrm{m}) / \mathrm{AlGaN}(0.1 \mu \mathrm{m}) /$ InGaN MQW/GaN $(0.1 \mu \mathrm{m})$ cap. The InGaN MQW segment contains five periods of InGaN well and barrier with a total thickness of $0.39 \mu \mathrm{m}$. The In concentrations in the well and

${ }^{a)}$ Electronic mail: pyyu@lbl.gov the barrier are nominally $20 \%$ and $2 \%$, respectively. All the layers are undoped. The band-gap energies in the $\mathrm{GaN}$ and AlGaN layers are in agreement with those reported in the literature. ${ }^{5}$

The PL spectra of our InGaN sample, cooled with a closed-cycle refrigerator, were excited by the $325 \mathrm{~nm}$ output of a $\mathrm{cw} \mathrm{HeCd}$ laser. Figure 1 shows the PL temperature dependence. At $T \geqslant 80 \mathrm{~K}$, the PL spectra show significant broadening on the high energy side. At $T<80 \mathrm{~K}$, the line shape becomes independent of $T$, and broader on the low energy side. The PL peak also exhibits at first a blueshift and then a redshift with increasing $T$. These features suggest that at $T>80 \mathrm{~K}$ the carriers have attained thermal equilibrium (are "thermalized") while at $T<80 \mathrm{~K}$ the carriers are not thermalized, presumably as a result of localization.

To understand quantitatively the temperature dependent PL line shapes, we use the following model. ${ }^{6}$ The optical transition matrix element is assumed to be constant and independent of the emission energy $E$. Furthermore, the electrons and holes involved in the recombination are free to move in bands with joint-density-of-states (JDOSs) $D(E)$ according to the Boltzmann distribution function $\exp \left(-E / k_{B} T_{e}\right)$, where $E$ is the carrier energy, $k_{B}$ is the Boltzmann constant, and $T_{e}$ is the carrier temperature. This model is only valid for temperatures much larger than the quasi-Fermi energy of photoexcited electrons and holes. The $\mathrm{PL}$ intensity $I(E)$ is then given by

$$
I(E) \propto f(E) \exp \left(-E / k_{B} T_{e}\right),
$$




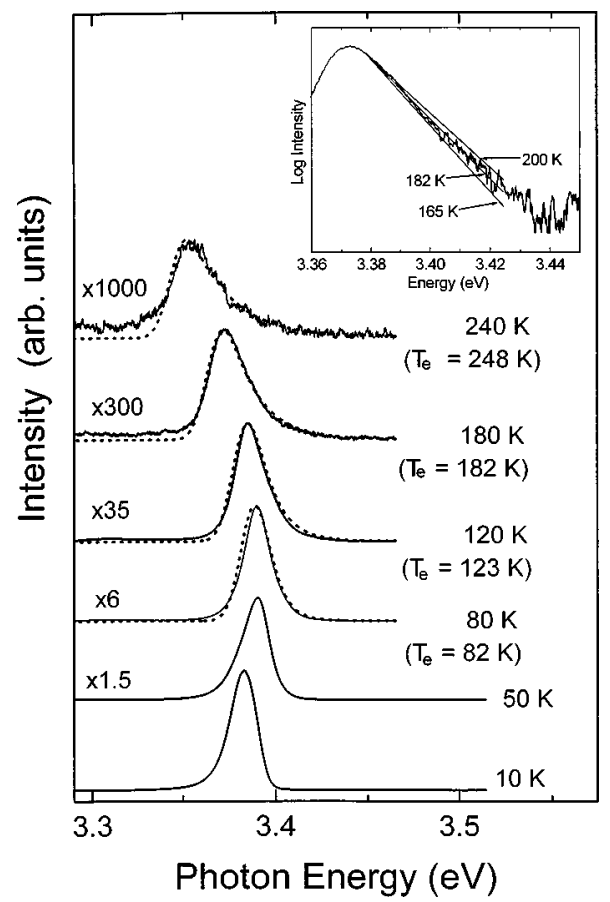

FIG. 1. Photoluminescence spectra of InGaN at different temperatures. The broken curves are fits to the experimental curves using Eq. (1). The inset illustrates the sensitivity of fitting to $T_{e}$ for the $180 \mathrm{~K}$ spectrum.

where $f(E)$ is the JDOS after convoluting with a Gaussian function $G(E)=\exp \left(E^{2} / \Gamma^{2}\right), \Gamma$ being a broadening parameter:

$$
f(E)=\int D\left(E^{\prime}\right) G\left(E-E^{\prime}\right) d E^{\prime} .
$$

To fit the experimental line shapes, we first determine whether $\ln [I(E)]$ has a linear dependence on energy, on the high energy tail of the PL peak. If so, the carriers are thermalized, and a well defined temperature $T_{e}$ can be extracted. The carriers in our InGaN sample became thermalized for $T \geqslant 80 \mathrm{~K}$, with $T_{e}$ in good agreement with the refrigerator temperature. This also indicates that laser-induced heating is insignificant. For such thermalized PL spectra we have attempted to fit the line shape with $D(E) \propto\left(E-E_{g}\right)^{n}$ for $E$ $\geqslant E_{g}$ and $D(E)=0$ for $E<E_{g}$, where $E_{g}$ is the band-gap energy and $n=0$ (free carriers in two dimensions) or $n$ $=0.5$ (free carriers in three dimensions). We find that all thermalized experimental PL spectra (i.e., those measured with $T \geqslant 80 \mathrm{~K}$ ) can be fitted quite well for $n=0$ with a constant $\Gamma=6.5 \mathrm{meV}$. The theoretical PL line shapes (broken curves) are compared with the experimental spectra in Fig. 1. The choice of $n=0$ implies that the photoexcited electron and hole pair in our InGaN sample behave like uncorrelated free particles in two dimensions. For $T<80 \mathrm{~K}$, the PL line shapes can no longer be attributed to thermalized carriers. This can be explained by the localization of carriers in fluctuating potentials, which prevents the carriers from reaching thermal equilibrium with each other. Since it takes thermal energies on the order of $k_{B} \cdot 80 \mathrm{~K}(\sim 7 \mathrm{meV})$ to excite the carriers out of these traps, we estimate an upper bound of 7 $\mathrm{meV}$ as the magnitude of the localization potential. The good agreement between the localization potential and the broadening parameter $\Gamma$ is expected if the fluctuation in the band

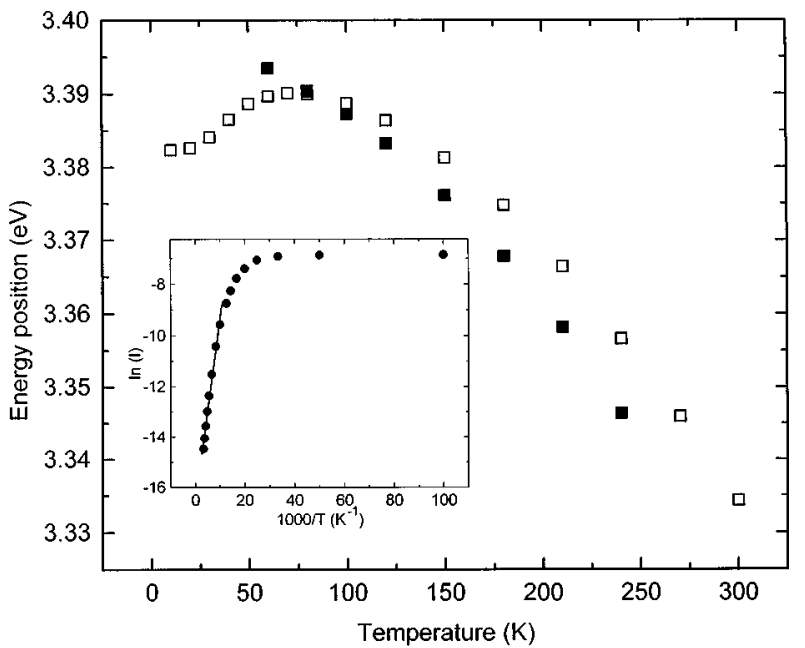

FIG. 2. Temperature dependence of the transition energy for InGaN. The open squares are the experimental PL peak energies, and the solid squares are the values for $E_{g}$, obtained by the fit using Eq. (1). The inset shows the Arrhenius plots of the PL emission intensity.

gap is responsible both for broadening $D(E)$ and localizing the carriers at low temperature. That the low-temperature PL blueshift can be explained by carrier localization is seen by comparing the PL peak energies with the band-gap energies deduced from the PL spectra fits (see Fig. 2). We notice that $E_{g}$ is smaller than the PL peak energy at high $T$, as expected. However, at low $T, E_{g}$ becomes larger than the PL peak energy. This can be explained by the nonthermal equilibrium distribution of carriers in traps with energies below $E_{g}$. The magnitude of the blueshift $(\sim 7.6 \mathrm{meV})$ from 10 to $80 \mathrm{~K}$, while not predictable by our model, is consistent with the values of $\Gamma$ and of the localization energy. A similar explanation of the low-temperature blueshift of the emission peak in InGaN is given by Eliseev et al. ${ }^{7}$

A similar PL temperature dependence is observed in the ternary alloys $\operatorname{In}_{0.5} \mathrm{Ga}_{0.5} \mathrm{P}$, pseudomorphically grown on GaAs. This alloy is known to self-organize into $\mathrm{Cu}-\mathrm{Pt}$ ordered domains under appropriate growth conditions. ${ }^{8}$ As a result of these domains, the PL line shape is inhomogeneously broadened. ${ }^{9}$ We have studied the temperature dependence of PL line shapes in a series of partially ordered and disordered InGaP alloys ${ }^{10}$ and found similarities to our In$\mathrm{GaN}$ sample. Our InGaP results are also similar to those reported by other groups. ${ }^{11}$ The InGaP samples' PL spectra can be fitted well by our theoretical model, except that the broadening parameters $\Gamma$ are smaller $(3.0$ and $2.5 \mathrm{meV}$ for one ordered and one disordered sample, respectively). The temperature $(\sim 40 \mathrm{~K})$ necessary to excite carriers out of the traps in these samples is also smaller (their localization energies are $\sim 4 \mathrm{meV}$ ). In InGaP the potential fluctuations have been established to be the result of variations in both alloy concentration and ordering. However, in InGaN the nature of these fluctuations has not been definitively determined. It is presumably the result of variations in the alloy concentration only, as suggested by other groups. ${ }^{2-4}$

Another similarity between PL in InGaN and $\mathrm{InGaP}$ is that both PL intensities are thermally quenched for $T$ $>50 \mathrm{~K}$. The inset in Fig. 2 shows an Arrhenius plot of the integrated PL intensity in InGaN. For $T>80 \mathrm{~K}$, the thermal 
quenching can be fit with an activation energy $E_{A}$ of 63 meV. Similarly, activation energies of 44 and $31 \mathrm{meV}$, respectively, are found in our ordered and disordered $\mathrm{InGaP}$ samples. These values are consistent with an increase in $E_{A}$ from 37.5 to $50 \mathrm{meV}$ reported by Lambkin et al. ${ }^{12}$ in $\mathrm{InGaP}$ with increasing degrees of ordering. It has been suggested that the measured activation energy $E_{A}$ in InGaN samples represents the localization energies of excitons, resulting from band edge fluctuations. ${ }^{13}$ Our analysis shows clearly that the localization energy and band-gap fluctuation in our InGaN sample is smaller than $E_{A}$ by almost 1 order of magnitude. Furthermore, the PL line shape indicates that carriers are free and thermalized for $T \geqslant 80 \mathrm{~K}$. Thus the thermal quenching activation energy must represent either a barrier to capture at nonradiative recombination centers, or the thermal activation energy of such centers. ${ }^{14}$ In the case of InGaP samples, the increase in $E_{A}$ with degree of CuPt ordering suggests that $E_{A}$ represents the barrier between the ordered domains (which have a lower band gap) and the disordered domain walls (having a higher band gap) containing the nonradiative centers.

In conclusion, we have demonstrated quantitatively the similarity in temperature dependence of the PL emission line shape of strained InGaN and partially ordered InGaP alloys. We show that in both materials the photoexcited carriers are localized and nonthermalized at low $T$. Their PL intensities are thermally quenched with an activation energy roughly an order of magnitude larger than the localization potential.

The work at Berkeley was supported by the Director, Office of Energy Research, Office of Basic Energy Sciences, Materials Sciences Division, of the U.S. Department of Energy under Contract No. DE-AC03-76SF00098.
${ }^{1}$ S. Nakamura, M. Senoh, N. Iwasa, and S. Nagahama, Jpn. J. Appl. Phys., Part 2 34, 2797 (1995); S. Nakamura, M. Senoh, N. Iwasa, S. Nagahama, T. Yamada, and T. Mukai, ibid. 34, L1332 (1995); S. Nakamura, M. Senoh, S. Nagahama, N. Iwasa, T. Yamada, T. Matsushita, H. Kiyoku, and Y. Sugimoto, ibid. 35, L74 (1996); L. J. Mawst, A. Bhattacharya, J. Lopez, D. Botez, D. Z. Garbuzov, L. De-Marco, J. C. Connolly, M. Jansen, F. Fang, and R. F. Nabiev, Appl. Phys. Lett. 69, 1532 (1996); E. Greger, K. H. Gulden, P. Riel, H. P. Schweizer, M. Moser, G. Schmiedel, P. Kiesel, and G. H. Dohler, ibid. 68, 2383 (1996).

${ }^{2}$ Y. Narukawa, Y. Kawakami, M. Funato, S. Fujita, S. Fujita, and S. Nakamura, Appl. Phys. Lett. 70, 981 (1997).

${ }^{3}$ W. Shan, B. D. Little, J. J. Song, Z. C. Feng, M. Schurman, and R. A. Stall, Appl. Phys. Lett. 69, 3315 (1996); S. Chichibu, T. Azuhata, T. Sota, and S. Nakamura, ibid. 70, 2822 (1997).

${ }^{4}$ P. Perlin, V. Iota, B. A. Weinstein, P. Wisniewski, T. Suski, P. G. Eliseev, and M. Osinski, Appl. Phys. Lett. 70, 2993 (1997).

${ }^{5}$ W. Liu, K. L. Teo, M. F. Li, S. J. Chua, K. Uchida, H. Tokunaga, N. Akutsu, and K. Matsumoto J. Cryst. Growth (to be published).

${ }^{6}$ K. Uchida, P. Y. Yu, N. Noto, and E. R. Weber, Appl. Phys. Lett. 64, 2859 (1994)

${ }^{7}$ P. G. Eliseev, P. Perlin, J. Lee, and M. Osinski, Appl. Phys. Lett. 71, 569 (1997).

${ }^{8}$ A. Gomyo, T. Suzuki, and S. Ijima, Phys. Rev. Lett. 60, 2645 (1988).

${ }^{9}$ E. D. Jones, D. M. Follstaedt, H. Lee, J. S. Nelson, R. P. Schneider, Jr, R. G. Alonso, G. S. Horner, J. Machol, and A. Mascarenhas, in Proceedings of the 22nd International Conference on the Physics of Semiconductors, edited by D. J. Lockwood (World Scientific, Singapore, 1995), Vol. 1, p. 293.

${ }^{10}$ K. Uchida, P. Y. Yu, J. Zeman, S. H. Kwok, K. L. Teo, Z. P. Su, G. Martinez, T. Arai, and K. Matsumoto, Mater. Res. Soc. Symp. Proc. 499 (1997).

${ }^{11}$ M. C. Delong, P. C. Taylor, and J. M. Olson, J. Vac. Sci. Technol. B 8, 948 (1990); F. A. J. M. Driessen, G. J. Bauhuis, S. M. Olsthoorn, and L. J. Giling, Phys. Rev. B 48, 7889 (1993); P. Ernest, C. Ceng, F. Scholz, and H. Schweizer, Phys. Status Solidi B 193, 213 (1996).

${ }^{12}$ J. D. Lambkin, L. Considine, S. Walsh, G. M. O'Connor, C. J. McDonagh, and T. J. Glynn, Appl. Phys. Lett. 65, 73 (1994).

${ }^{13}$ M. Smith, G. D. Chen, J. Y. Lin, H. X. Jiang, M. Asif Khan, and Q. Chen, Appl. Phys. Lett. 69, 2837 (1996).

${ }^{14}$ I. A. Buyanova, W. M. Chen, G. Pozina, B. Monemar, W. X. Ni, and G. V. Hansson, Appl. Phys. Lett. 71, 3676 (1997). 